\title{
Analytical Insights on the Position, Challenges, and Potential for Promoting OER in ODeL Institutions in Africa
}

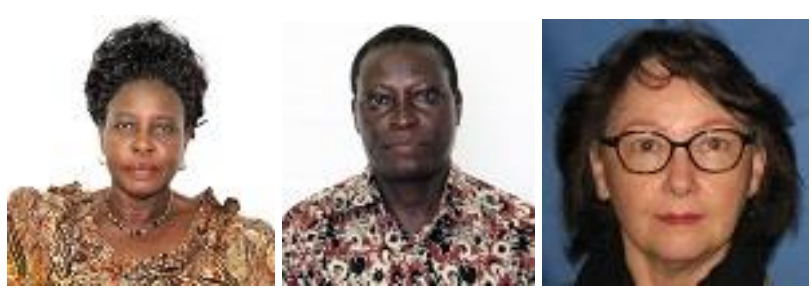

Cornelia K. Muganda', Dr Athuman S. Samzugi', and Brenda J. Mallinson²

1 Open University of Tanzania, ${ }^{2}$ OER Africa / Saide

\begin{abstract}
This paper shares analytical insights on the position, challenges and potential for promoting Open Educational Resources (OER) in African Open Distance and eLearning (ODeL) institutions. The researchers sought to use a participatory research approach as described by Krishnaswamy (2004), in convening a sequence of two workshops at the Open University of Tanzania (OUT) as a strategy for collecting data to obtain the aforementioned insight. The principal workshop objectives were to analyse the existing status of OER at the OUT and subsequently to share lessons learned in OER creation and production, integration and use, and hosting and dissemination. Other objectives were to discuss the rationale for an institutional OER policy and identify a suitable work-flow process for developing OER at the OUT. The workshop participants were purposively selected for their experience in co-developing OER materials with various outside organisations. The study included 28 representatives of the OUT academic units, and one facilitator from OER Africa. Research techniques used to collect data included a questionnaire, focused group discussions, presentations, and panel discussions. Results indicated that OUT staff were willing to engage with OER but had limited awareness, skills and competencies in the creation, integration and use of OER. The outcome of the study was the development of nine draft OER resolutions expressing needs that include the development of a comprehensive institutional OER policy related to existing institutional policies in order to guide, support and promote research and sustainable OER practice via holistic participation. Enabling strategies included capacity building, increased internal and external collaboration, and enhanced access to and visibility of OER via the institutional repository.
\end{abstract}

Keywords: OER, participatory action research, institutional approach, ODeL, adoption 


\section{Introduction}

In developing countries such as Tanzania, higher education institutions tend to use much time, but with limited resources, when designing learning materials. Such situations are caused by the increased cost of textbooks and other printed and electronic resources from commercial companies.

Thus, as Open Distance and eLearning (ODeL) institutions in Africa strive to widen opportunities for quality education under restricted funding, the increased use of Open Educational Resources (OER) becomes essential to the successful operation of institutions. However, the literature indicates a paucity of OER developed in Africa, as well as challenges of limited awareness, limited capacity, doubt in the quality and credibility of OER, intellectual property issues, and lack of clear policies to guide OER creation, development, dissemination, use and quality assurance. The Open University of Tanzania (OUT) is currently both a co-developer and beneficiary of OER generated under the auspices of other institutions such as the African Virtual University (AVU) and the Teacher Education in Sub Saharan Africa (TESSA) project, which indicates that the OUT recognises the importance of OER. Despite the conceptual importance attached to OER in teaching, learning, research and widening access to education at the OUT, there was no analytical insight on the potential for promoting OER at the OUT. Therefore, in order to get a holistic institutional picture of OER it was deemed important to conduct the study to establish the position, challenges and potential for promoting OER internally. This was undertaken because of the immense potential benefit of the use of OER materials for promoting wider access to education as well as improving the quality of programmes offered by the OUT The current study, therefore, contributes to the understanding of OER implementation at OUT.

\section{Literature Review}

The relevant literature that was reviewed indicated the challenges of designing and accessing learning resources by higher education institutions in developing countries like Tanzania. The challenges include the increased cost of textbooks and other printed resources from commercial companies. Mtebe and Raisamo (2014) for example, argue that printed resources are expensive, lack contextual relevance, and are difficult to share with wider groups of students (p. 250). The literature also highlights the potential of OER to meet these challenges and enhance the quality of education. As Walji (2014) asserts, OER are needed to widen access and enhance quality of non-formal education, in a perspective of lifelong learning and to improve both cost-efficiency and quality of teaching and learning outcomes. In fact, the use of such materials has the advantage of removing the barriers to accessing current and relevant materials which have been prepared, developed and reviewed by various experts. Wright and Reju (2012) contend that the use of OER in higher education can widen access to education, reduce the costs and improve the quality of education because the instructors and learners can easily access resources that they were previously unable to access due to the cost or copyright laws (p. 181). Butcher (2011) also stresses that instructors can use these open education resources to improve the quality of existing courses or develop new courses by adapting the existing courses (p. 13). Thus, OER provide the potential to widen access to education both formal and informal at all levels. Mushi and Muganda (2013) challenge and encourage African intellectuals to develop OER which can be shared among themselves and others world-wide. 
Thus, being part of the OER movement is not optional but a necessity for the African academic community. What is important is knowledge and strategies to promote effective development, use, integration, hosting and dissemination of OER within the context.

Definitions of participatory research in some existing literature (Krishnaswamy, 2004, Mor, Warburton, \& Winters, 2012) assisted the researchers' choice to employ a participatory methodology for the study. According to Krishnaswamy (2004), participatory research represents people as researchers in pursuit of questions encountered in daily life (p. 1). Similarly, Mor, Warburton, and Winters (2012) describe the "Participatory Methodology for Practical Design Patterns" as a process by which communities of practitioners can collaboratively reflect on the challenges they face and the methods for addressing them (p. 4). The outcome of the process is a set of design narratives, design patterns and design scenarios situated in a particular domain of practice. This methodology was used because the researchers wanted to obtain analytical insights on the position, challenges and potential for promoting OER at the OUT.

\section{Study Objectives}

Accordingly, the present study was planned with the following specific objectives: analyse the current status of OER at the OUT; share lessons learned in OER creation, development and production; share lessons learned in OER integration and use; share experience in OER hosting and dissemination; discuss the rationale for an institutional OER policy; and identify challenges and potential of OER.

\section{Research Methodology}

The study upon which this paper is based employed descriptive qualitative research design and was conducted at the OUT. A sequence of two workshops were convened at the OUT as a strategy for collecting data to obtain the aforementioned insight. The initial workshop addressed the first objective, while the subsequent workshop addressed the remaining objectives

The participants were purposively sampled. According to Punch (2003), purposive sampling is a technique employed with some particular purpose in mind (p. 187). For this study, the criteria used in formulating the categories of respondents were information-rich people who are knowledgeable about OER and lecturers who have integrated and used OER materials for teaching and learning at the OUT. Ten academic staff members who participated in developing AVU and TESSA materials were included in order to share the experience gained in those two projects. A further 14 members were selected from faculties and departments that use OER materials to complement study materials generated by the OUT and three members were from the OUT library. The library was involved because of the nature of their duties which compel them to promote the usage of the materials. One facilitator from OER Africa was involved based on her experience in the field of OER.

The methods used to collect data were questionnaires containing open ended questions, focused group discussions (FGD), and workshop presentations and panel discussions. The questionnaires were distributed to academic staff selected from faculties that use OER materials to complement study materials generated by the OUT and from the OUT library. The results obtained from questionnaires formed the basis of the FGDs and panel discussions during the workshops. 
FGDs were conducted at Faculty levels to validate the responses received through questionnaires. Two groups from Faculty of Education and Faculty of Science and Technology and Environmental Studies participated in FGDs. As was the case with the questionnaire, the FGDs were focused on the OER Institutional Analysis Each group comprised six people. The selection of the sample was based on a model provided by Stewart and Shamdasani (1990) who recommended a group of 6-12 participants, arguing that an FGD with fewer than six participants was likely to lead to a dull discussion (p. 59). During the discussions, participants were encouraged to talk freely and interact with the expectations to build on one another's comments. As Cohen, Manion, and Morrison (2000) note, group interactions allow for quality data to emerge (p. 305). Through FGDs participants were able to air views and experiences on the issue under investigation. This method was chosen because the subject of OER, which was under investigation, is fairly new in Tanzania and not much literature has been documented in the region. Therefore, the use of FGD was considered ideal based on its strength in allowing participants to share their views.

Secondly, the FGDs were conducted during the first workshop which was held on $24^{\text {th }}$ November 2014. Six OUT departmental groups were invited to the workshop: the Institute of Educational Management Technologies (IEMT) and Faculties of Education, Life Sciences, Economic Law, Library Services, as well as Linguistics and Literary Studies. Each group worked through a planning document, engaging fully with the task over the course of the day. The activities followed a Maturity Definition process provided by South African Higher Education Learning Analytics (SAHELA, 2014) adapted by Saide for OER Institutional Analysis which addressed the following issues: defining the current learning and teaching challenge; DESIGN worksheet: Needs analysis; DESIGN Worksheet: Leadership; and OER Maturity Index comprising a series of quantitative questions regarding Expertise, Policy and Procedure, Quality Assurance, Infrastructure, Culture and Leadership and Investment. The data for these dimensions was collated with each group calculating an overall Institutional OER Maturity index.

To supplement and validate the information collected through FGDs, a participatory pattern (second) workshop was organized in January 2015. In order to adhere to this methodology, academic staff members who participated in completing the questionnaire, and participated in the FGD were again invited to the workshop to discuss and deliberate on data collected through questionnaires and FGD. The guiding themes were OER institutional analysis, experiences on development, production, integration and use, and hosting and dissemination of OER. The academic staff was invited to share their experiences of OER by making presentations that were followed by panel discussion sessions. All important issues emerged from the discussions were recorded as proceedings. At the end of the workshop, participants emerged with the draft resolutions providing suggestions for further improvement of OER at the OUT.

\section{Results and Discussion}

This part presents the findings and discussions in relation to the objectives of the study.

\section{Distribution of Respondents}

The demographic question was asked for the purpose of keeping statistics of the faculties which participated and responded with relevant information for analysis and discussion. For the present study, 23 respondents from seven faculties, institutes and directorates were involved. Out of the 23 
questionnaires distributed all were completed and returned. The sample yielded $100 \%$ return rate. Faculties, Institutes and Directorates were involved in the study because by the nature of their work they are supposed to orient their students on various resources relevant to their programmes including OER. Figure 1 presents the distribution of respondents:

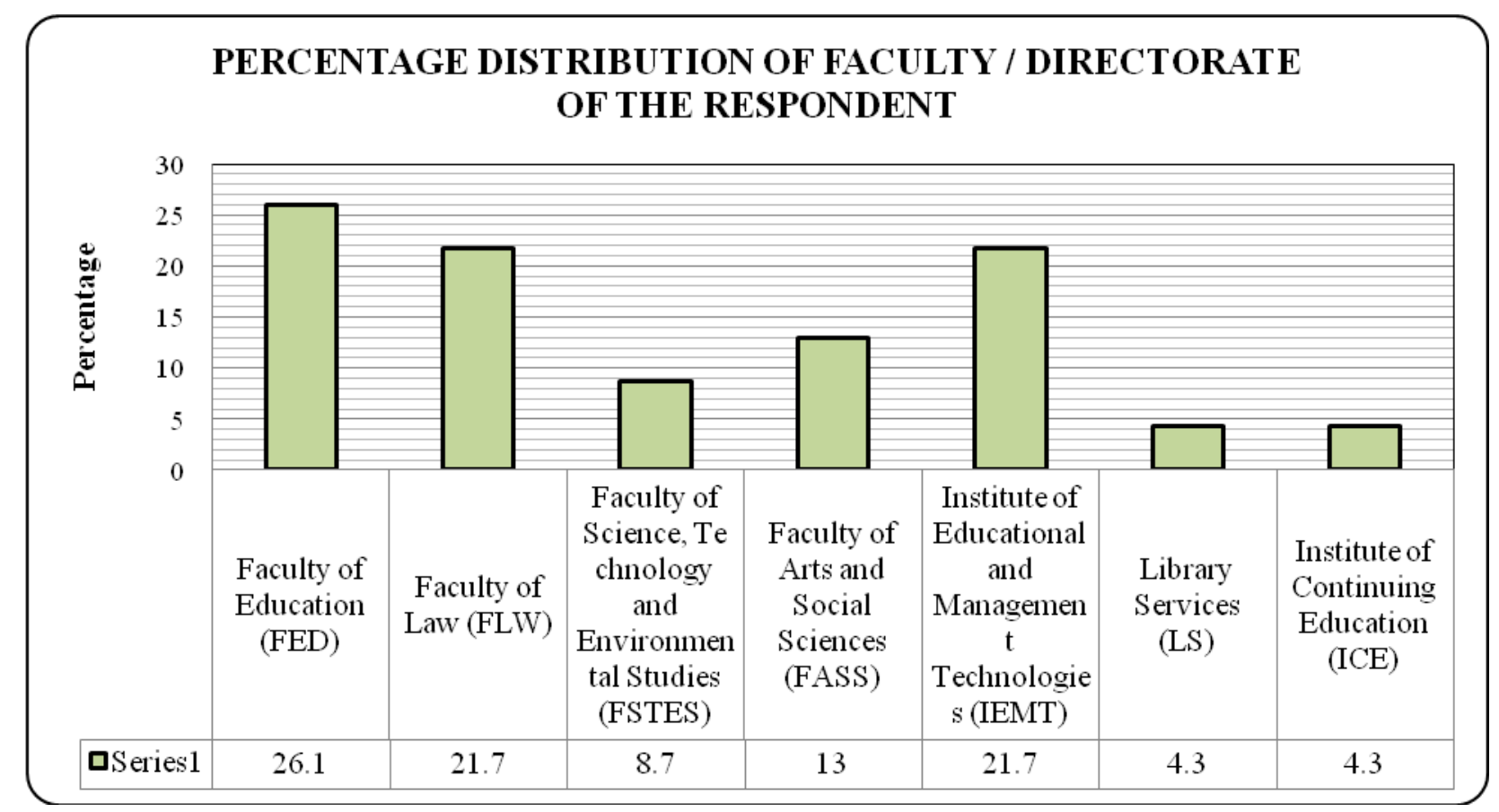

Figure 1. Distribution of respondents.

In the questionnaire respondents were asked whether they are aware of the existence of OER. This question was asked because the use of resources in whatever format is influenced by knowing of their existence. Twenty-two (95.7\%) respondents reported that they were not aware on the existence of OER, while one (4.3\%) indicated awareness of their existence. Based on these responses one of the workshop participants stated that "there is a need to promote OER and the University should start developing its OER in collaboration with other institutions in the country based on the experience gained through AVU and TESSA." The findings are consistent with similar studies by Mtebe and Raisamo (2014, p. 6), and Samzugi and Mwinyimbegu (2013, p. 82). The responses from respondents indicate there is a need to craft and implement an awareness campaign because the survival of the university in this globalised world will depend much on the availability and use of OER.

To establish the usage and access levels of OER, respondents were asked to indicate the extent to which their faculties are using OER and the reasons for using them. Twenty (87\%) of the respondents indicated that they are using OER while three (13\%) were not using OER. The majority (60\%) indicated that OER are used to supplement the existing study manuals (lecture notes), followed by52.2\% (reference materials), compatible to the faculty programmes (47.8\%). Only a few (21.7\%) agreed that OER are easy to understand. Respondents were asked to indicate the extent to which OER is compatible with the faculty programmes. More than half $(12,52.2 \%)$ indicated that OER are not compatible to their programme; only 11 (47.8\%) were in agreement that OER are compatible to the offered programmes. The reasons given for not using OER were that they are difficult to access (100\%), "University does not encourage their use" (95.7\%), not aware of their existence (87.0\%), no 
idea about the quality of use OER (87.0\%), and the thinking that OER are not relevant to the courses (87.0\%).

On the types of OER used at the OUT it was revealed that AVU Courseware is the most popular (56.5\%), followed by the OUT courseware (47.8\%), TESSA OER (39.4\%) and MIT courseware (34.8\%). Lesser used are Yale University Open courseware and others. Figure 2 explicates the respondents' view of the reasons why faculty uses OER, while Figure 3 shows the types of OER that are frequently used by faculty.

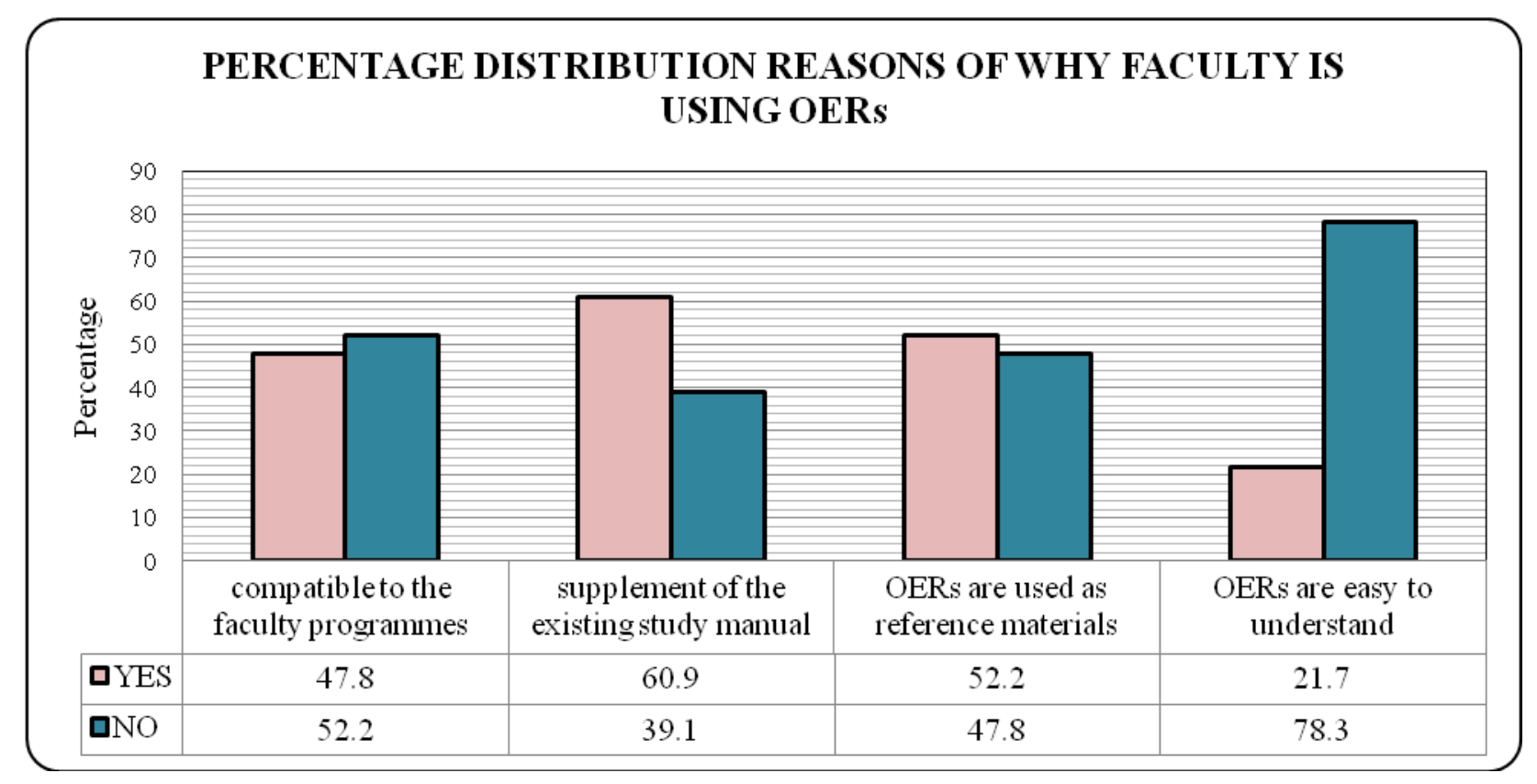

Figure 2. Why faculty use OER.

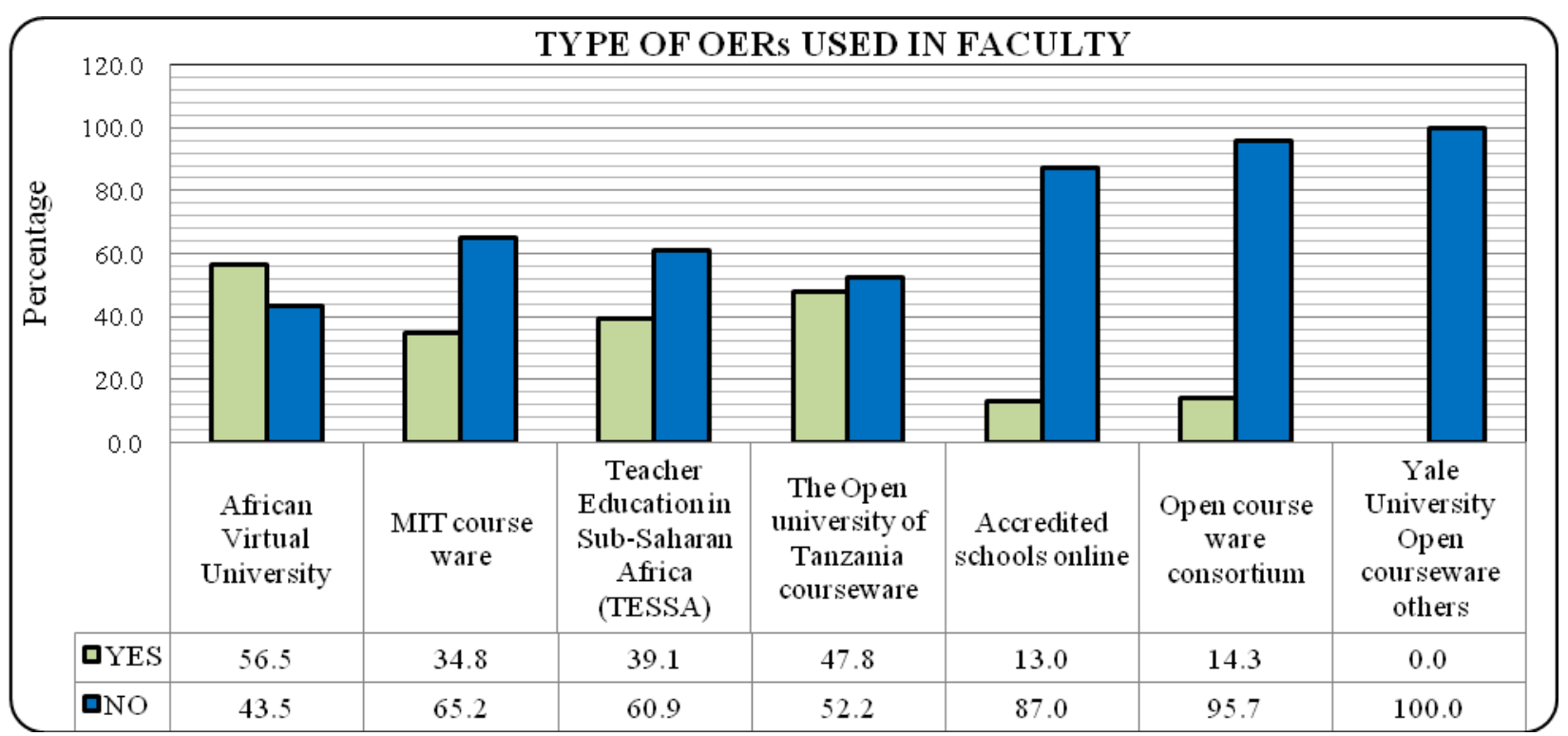


Figure 3. Types of OER frequently used.

OER are intended to be used to support quality teaching, learning and research. For lecturers to recommend available OER to their students/users they need to ascertain their quality. Faculties were asked to give their views on the quality of OER (Figure 4). Out of 23 respondents, 13 (56.5\%) indicated Good, five (21.7\%) indicated Excellent, and four had no comment (17.4\%). The overall picture suggests that the majority of respondents are of the view that OER are good materials. Perhaps this is because some of the members of staff have participated in co-developing OER within initiatives such as AVU and TESSA which are relevant to the Faculties of Education and Science. For those indicating "no comment" they may not have been exposed to OER relevant for their respective programmes.

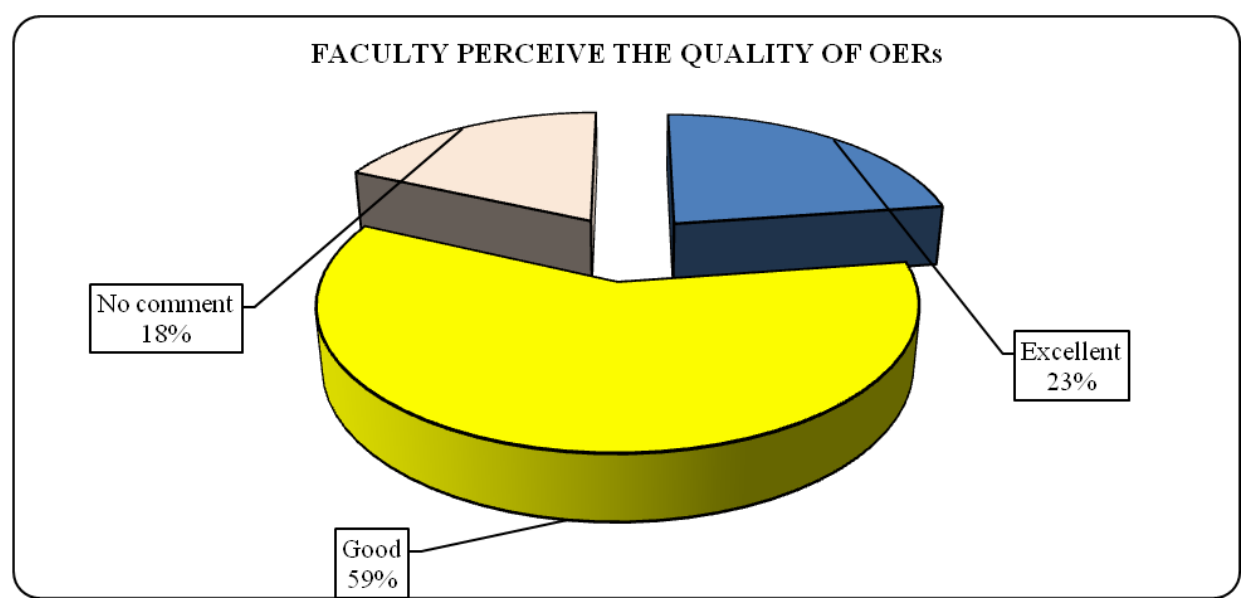

Figure 4. Perceptions on quality of OER.

Quality Gurus (2011) states that Quality Control is defined as "The operational techniques and activities used to fulfil requirements for quality". Respondents were asked about the mechanisms used to ensure the quality of OER at the OUT. Out of 23 respondents, 14 (74\%) indicated that there are staff dedicated to quality assurance, five (26\%) indicated that there are quality guidelines, while on the issue of copyright clearance of the third party materials, no respondents responded that there were procedures in place. At the OUT there is a study material policy as well as research policy in place which ensures the quality of all publications emanating from the university. Under this policy all materials including OER are subjected to internaland external reviews, and editing is important to ensure the quality of learning materials. Workshop participants suggested that content experts be used to ensure quality of OER development and usage by OUT staff and students. Proper citation and acknowledgement of source(s) were suggested as a best practice to minimize plagiarism (FGD).

On the issue of copyright, staff engaged in the writing of materials are informed of required adherence to copyright issues. During the workshop, participants reported that "determining the appropriate creative common (CC) license to use is vital". It was noted "further that there is a need of careful selection of those which are suited for the purpose because CC licences are varying" (Workshop, 2015). However, since none has responded to the issue of clearance of the third party copyright in the questionnaire it seems this is a significant problem. Therefore, in order to avoid the infringement of copyright there is a need to raise awareness among staff that OER are either in the public domain or free based on a creative commons licence and formation of licence clearance office. The findings are in line with that of Ncube (2011) who cautions that the production of OER should be supported by 
significant institutional policy and practices such as necessary copyright clearance procedures. Figure 5 shows the responses on Mechanisms to ensure quality of OER Source.

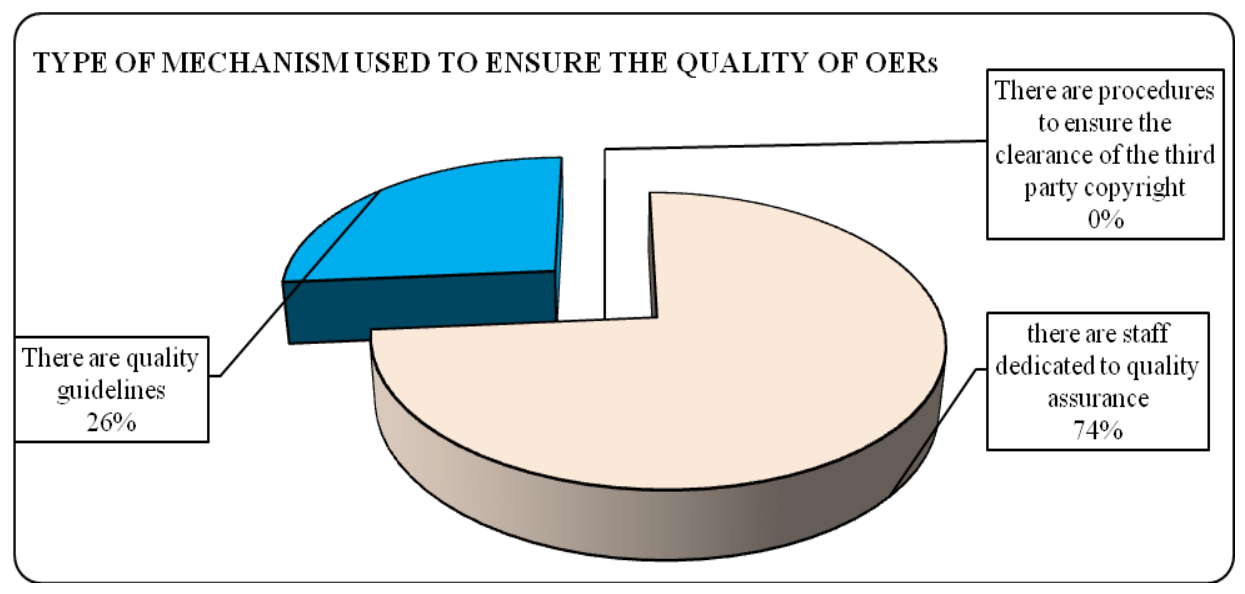

Figure 5. Mechanisms to ensure quality of OER Source.

Generally, the knowledge or understanding of the value and central role of OER starts with the faculty because they are the teaching institutions. Responding to the question regarding whether faculties are involved in the creation, development and promotion of OER, 18 (78.3\%) indicated that they are involved while five (21.7\%) indicated they are not. This implies that the majority are involved. However, caution should be taken because some might think that study materials (lecture notes) are synonym to OER. Further probing on the types of OER created by faculties revealed that $65.5 \%$ indicated Textbook/Lecture Notes, followed by tutorials (17.4\%) and group lessons (13\%).The overall picture suggests that faculties are engaged in production of lecture notes some of which are freely available although there are no licensing symbols inserted on them. For details refer to Table 1.

Table 1

Type of OER Created by Faculty

\begin{tabular}{|c|c|c|c|c|c|c|}
\hline & & $\begin{array}{l}\text { Textbook/Lect } \\
\text { ure Notes }\end{array}$ & Tutorials & Group Lessons & $\begin{array}{l}\text { Learning } \\
\text { Objects }\end{array}$ & $\begin{array}{lr}\text { Other } & \text { Types } \\
\text { of } & \text { OER } \\
\text { Created } & \end{array}$ \\
\hline \multirow[t]{3}{*}{ Valid } & YES & 65.2 & 17.4 & 13.0 & 13.0 & 13.0 \\
\hline & NO & 34.8 & 82.6 & 87.0 & 87.0 & 87.0 \\
\hline & Total & 100.0 & 100.0 & 100.0 & 100.0 & 100.0 \\
\hline
\end{tabular}


Respondents were asked to identify factors which could facilitate the creation, development and production of OER. The data collected indicates that institutional support and institutional policies are key (69.6\%) in facilitating the creation, development and production of OER. This was followed by infrastructure (47.8\%). The Open University of Tanzania scheme of service for academic staff (2015) recognises OER materials for the promotion of academic staff. Apart from promotion, a staff member is given financial incentives for the creation, development and production of OER. Figure 6 displays the factors for facilitating the creation, development and production of OER.

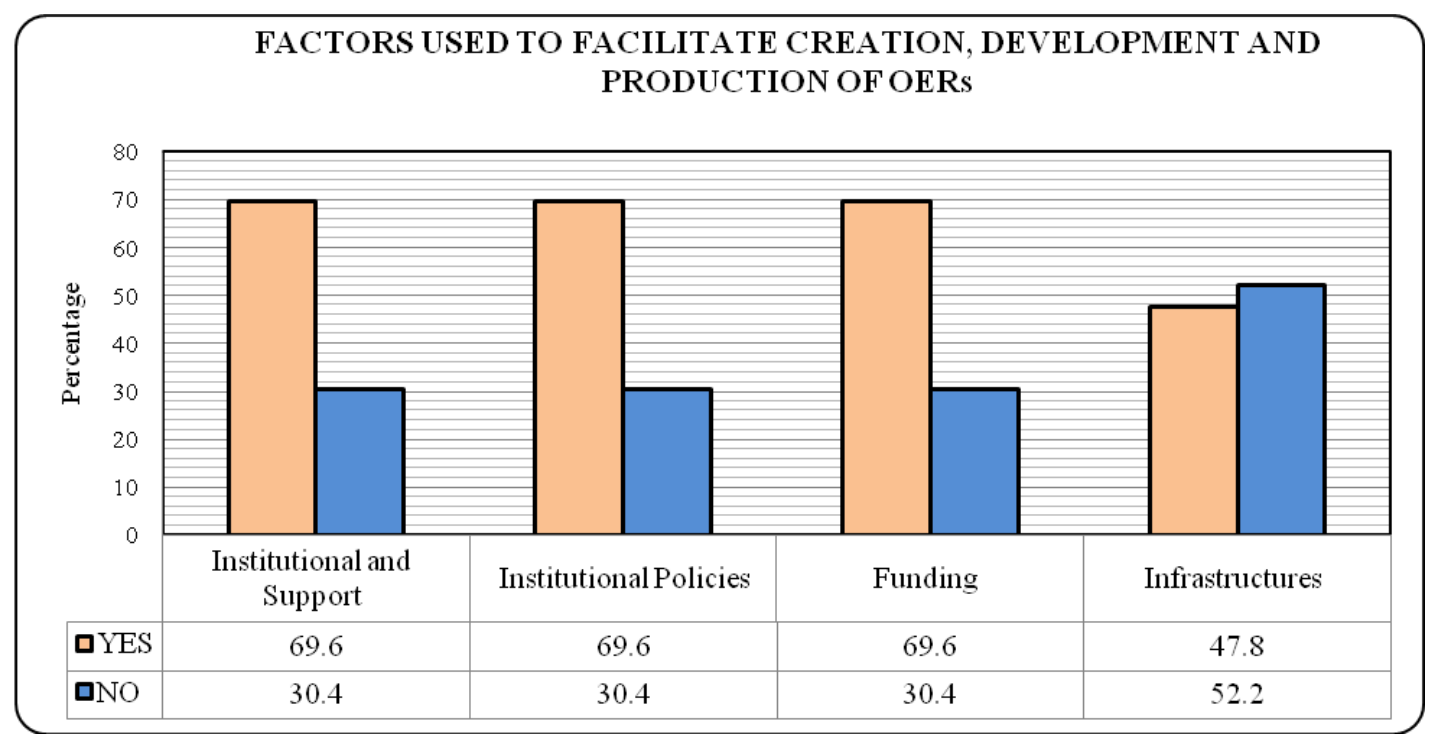

Figure 6. Factors for facilitating creation, development and production of OER.

In order for staff to create quality OER materials they need skills or experience. Respondents were asked whether they have skills or experience in developing OER materials. Fourteen (60.9\%) indicated they have experience and nine (39.1\%) have neither skills nor experience in OER creation. Although OER Africa, AVU and TESSA have done a commendable job in imparting knowledge and skills to staff (60.9\%), there is an urgent need to conduct more training to cover capacity building for many more staff. Also respondents were asked how they acquired the skills. The results show that they acquired skills through various methods. Learning through workshop and seminars (47.8\%) participation in OER production at the institutional level (47.8\%), through peers (39.1\%), and through online tutorials (26.1\%) were the main sources of acquiring skills by staff in the university. University and other champions of OER could consider it to be included as a subject in university curriculum in order to train many experts in this emerging field of information source especially in developing countries. As already discussed elsewhere, respondents reported that they have participated in developing OER materials. The results indicate that the majority of respondents participated in developing OUT courseware (39.1\%) followed by the Digital Fluency course (34.8\%) which is facilitated by OER Africa, and few staff were involved in developing materials for TESSA (8.7\%) and AVU (8.7\%). These results show that developing OER materials is fairly new to Tanzania. Through FGDs, it was reported that although OUT staff participated in OER they had limited awareness, skills and competencies in the creation, development, integration and use of OER. Thus, OUT staff were less confident and hesitant to develop and use OER. Also lack of a comprehensive policy which is directly addressing OER issues creates a vacuum in undertaking OER endeavours. This may lead to not giving due priority to OER in the process of enhancing teaching and learning. It was noted that sometimes, 
while the institution is allowing their staff to take time to participate in OER development workshops, the institution may not recognize that writing an OER material was an additional workload (FGD). In order to redress the situation, there is a need for the OUT to take a proactive step in conducting more in-house training and sensitising staff to convert their materials to OER. One participant observed further that capacity building in OER should be part of the professional development of OUT staff (Workshop).

Developing OER materials needs particular skills. Participants were asked to suggest the types of skills needed in developing OER. Out of the 23 respondents asked this question, most indicated they need skills in material design, development and production (91.3\%), information and communication technology (ICT) (78.3\%) skills in intellectual property rights (60.9\%), and skills to develop web platforms (52.2\%).

Policy support is vital for OER to reach potential at the university because it gives a bearing on what should be done. Sixteen out of 23 respondents (69.7\%) reported they don't know if the university has an OER policy, five (21.7\%) mentioned that there is no policy and two (8.7\%) indicated that there is a policy. These results show that there is no effective policy guiding the creation and production of OER. The existing policies such as Study Materials Policy, the Quality Assurance Policy and the Library Policy are currently silent on issues related to OER. However, OER is mentioned in the ICT policy 2014/15 -2018/19 section 2.2.3 item (k) which states that "The University shall develop guidelines on creating and adoption of Educational Resources E.g. Open Educational Resources, MOOCs and other innovative ICT related educational resources.” The ICT Master Plan 2014/15 -2018/19 section 4.9.3 item (e) states that OUT will "develop OER policy." Similarly, the OUT Quality Assurance Policy (2008) although it does not mention OER has some statements which are indicative of the need for OER. The Quality Assurance Policy (2008) emphasizes the need to "ensure timely availability of up to date and quality study materials to meet the increasing student enrolment". Furthermore, the Quality Assurance Policy also states that "the University shall strive to enhance easy and timely provision of complete course packages in both print and electronic form" and lastly the policy seeks "to enhance awareness and knowledge of students, staff and course materials developers on all forms of intellectual property rights". The analysis of various documents has revealed that there is no approved OUT OER policy in place despite importance attached to OER in the improvement of learning and teaching and in ODeL philosophy. The findings corroborate with that of Mtebe and Raisamo (2014, pp. 13-14), who found that lack of policies at an institutional level was a major barrier to the use of OER in the surveyed institutions.Therefore, there is a need to develop an OER policy to guide OER development, integration and use at the OUT. In probing further, respondents were asked whether there is plan to develop a policy. Twenty-five percent were in agreement though a significant number of respondents (50\%) indicated otherwise. These results show that the majority of respondents are not aware of the plans of the university regarding OER. Figure 7 portrays the level of awareness of the respondents of the plans of the university regarding OER. 


\section{PERCENTAGE DISTRIBUTION IF INSTITUTION HAVE OERs POLICY \\ GUIDING CREATION AND PRODUCTION}

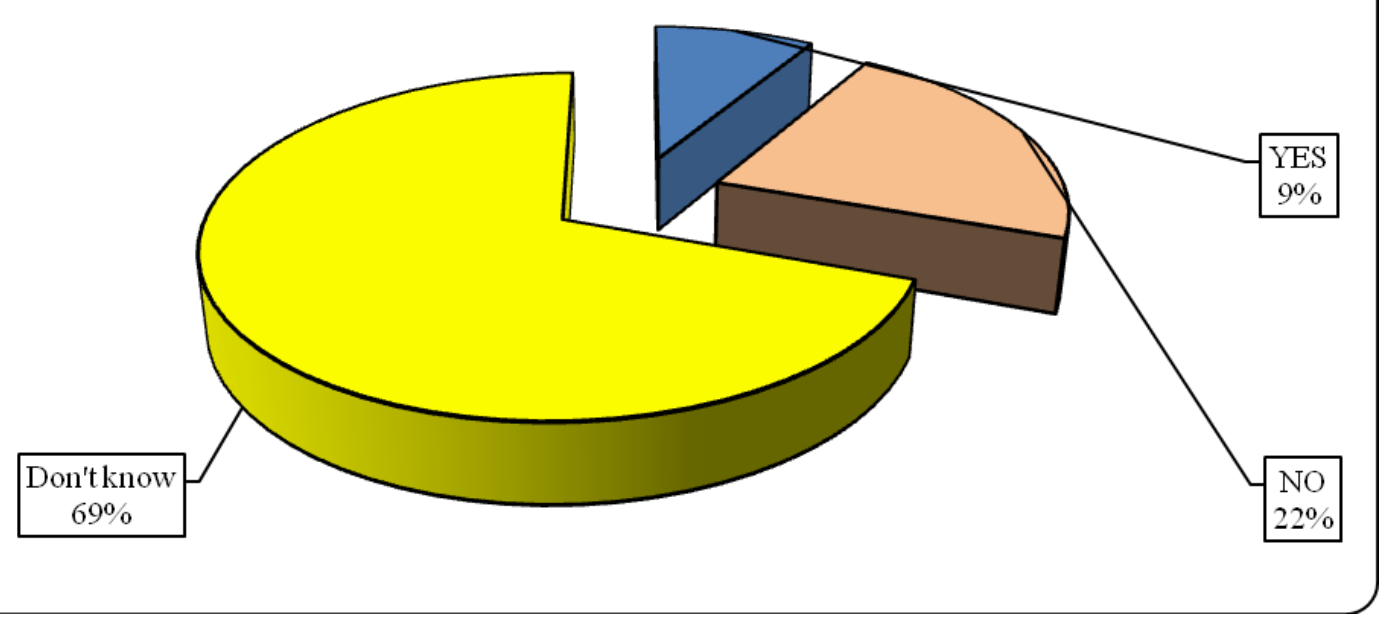

Figure 7. Awareness of whether the University has an OER policy.

The potential offered by OER in ODeL in a developing country like Tanzania is immense. Among the potential benefits identified by the respondents are that it enhances lifelong learning (78.3\%), increases scientific knowledge at the university (69.6\%), is cost effective to access current scientific information (65.2\%), and offers scholars opportunities to disseminate their scientific works (39.1\%).

A wide range of issues were raised by the respondents. The most mentioned challenge related to using OER was the lack of skills to develop OER (78.3\%) followed by inadequate knowledge on copyright issues (69.6\%), lack of technological support (69.6\%), lack of awareness on their existence (69.6\%), and unwillingness to use OER. Generally, there was a higher level of agreement than disagreement across all items. On the issue of copyright workshop participants observed that the existing Copyright and Neighbouring Rights Act 1999 in section 12(3) envisages that a teacher in the physical classroom environment is allowed to use and distribute materials for educational purposes. Neither the distance education environment nor OER are considered in this national law. Discussion from the group recommended that elements of the physical classroom requirements which are envisaged in the Copyright Act should be replaced by "teaching environment" to enable distance education to make use of modern technologies to access and share various sources of information and knowledge including OER (Workshop). The recommendation made agree with those of Samzugi and Benhajj (2001) who recommended the need to amend the law in order to provide specific statutory exemptions to copyright infringements designed to cover activities which will be regarded as permissible under the general heading of education use which should incorporate distance education (p. 128). Figure 8 shows the challenges to using OER. 


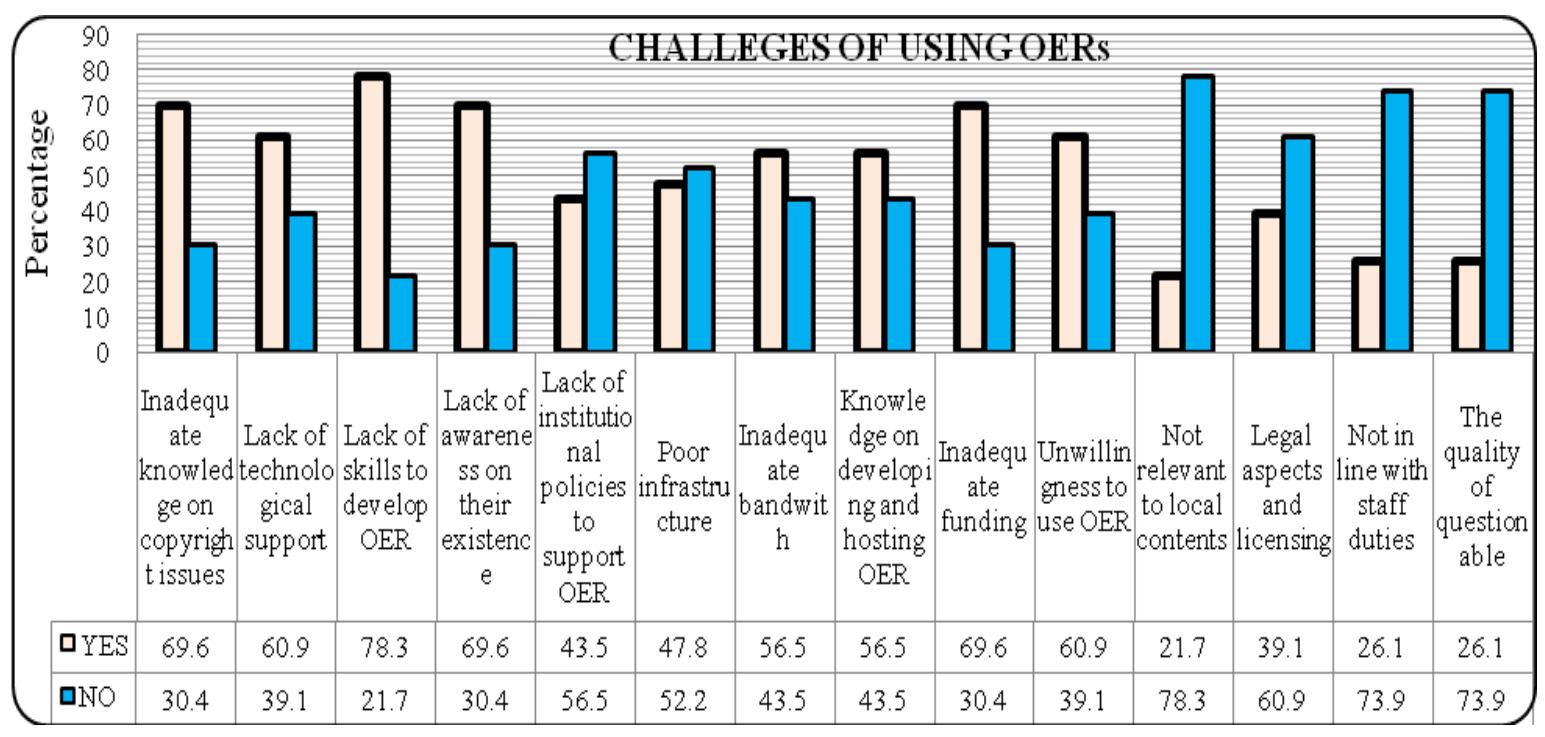

Figure 8. Challenges to using OER.

\section{Recommendationsand Conclusion}

Based on the survey and workshops the following recommendations were made to OUT management. It was recommended that since the university has started to embrace OER there is a need to develop OER policy to guide procedures and practices. In terms of raising awareness on the centrality of the role of OER in the ODeL environment, the issue of creating awareness and sensitization workshops on a regular basis on the production, use, integration, and sharing experiences for improving the OER practices at the OUT was highlighted. Methods to be used include the showcasing of experiences of OER participation of all staff, and harnessing and integrating experiences in OER production and use at the OUT. Other recommendations which came out from the study is the need for the university to be proactive in building the capacity of its staff members in the production, integration and use of OER. Lecturers should be encouraged to incorporate and recommend OER to their students.

In a situation where resources are scarce, collaboration with other institutions within and outside Tanzania in the production, integration and use of OER should be encouraged. At the same time, it was emphasised that the issue of quality of OER should be given priority and it was recommended to urgently incorporate OER issues in the review of the Quality Assurance Policy as well as in the Study Materials Policy.

OER can make significant contributions in enhancing the access to quality education that is relevant or can be made to be relevant to particular contexts. While OER are increasingly being embraced in Africa, ODeL institutions are still lagging behind in terms of engaging holistically in the OER movement. The challenges highlighted in this paper notwithstanding, there still exists untapped potential in terms of building human resources capacity in this area. African institutions, particularly ODeL institutions, have staff who have participated in the development, production, versioning, integration and use of OER. They are rich in experiences and that can be harnessed for OER production, integration and use in Africa. Overall, the OER focussed action workshops have made a significant contribution to understand the current status and furthering the institutional practices of OER at the OUT. The significance of this research and practice is that an institutional participatory action approach such as that described in this paper, can assist in identifying such potential while 
taking into account what we need in order to move forward. The authors believe that this approach can be introduced to other institutions, followed by national and regional initiatives to provide opportunities for institutionalisation and cross-institutional sharing of OER.

\section{References}

Butcher, N. (2011). A basic guide to open educational resources (OER). COL (Vancouver) and UNESCO (Paris). Retrieved from http://www.col.org/PublicationDocuments/Basic-GuideTo-OER.pdf

Cohen, L., Manion, L., \& Morrison, K. (2000). Research methods in education (5 $5^{\text {th }}$ ed.). London: Routledge.

Krishnaswamy, A. (2004). Participatory research: Strategies and tools. Practitioner: Newsletter of the National Network of Forest Practitioners, 22, 17-22. Retrieved from http://nature.berkeley.edu/community forestry/Workshops/powerpoints/tools\%20and\%20 strateg es\%20of\%20PR.pdf

Mor, Y., Warburton, S., \& Winters, N. (2012). Participatory pattern workshops: A methodology for open learning design inquiry. Research in Learning Technology, 20. Retrieved from http://www.researchinlearningtechnology.net/index.php/rlt/article/view/19197

Mtebe, J. S., \& Raisamo, R. (2014). Challenges and instructors' intention to adopt and use open educational resources in higher education in Tanzania. The International Review of Research in Open and Distributed Learning, 15(1). Available online at http://www.irrodl.org/index.php/irrodl/article/view/1687/

Mushi, M. K., \& Muganda, C.K. (2013). Open education resource for national development. JIPE, 5(1).

Ncube, C. B. (2011). Key copyright issues in African distance education: a South African case study. Distance Education, 32(2), 269-275.

The Open University of Tanzania Quality Assurance Policy. (2008). Dar-es-Salaam, Tanzania

The Open University of Tanzania Study Material Policy. (2008). Dar-es-Salaam, Tanzania

The Open University of Tanzania Information and Communication Policy. (2014). Dar-es-Salaam, Tanzania

The Open University of Tanzania. (2015). Scheme of service and guidelines for academic staff performance evaluation at the Open University of Tanzania. Dar-es-Salaam, Tanzania

Punch, K.F. (2003). Survey research: The basics. Sage Publishing. Retrieved from https://au.sagepub.com/en-gb/oce/survey-research/book224875

QualityGurus (2011, February). Difference between quality assurance and quality control: The summary of discussions at QualityGurus.com. Document QMoo1. Retrieved from 
http://www.qualitygurus.com/download/QMoo1DifferenceBetweenQualityAssuranceAndQu alityControl.pdf

South African Higher Education Learning Analytics. (2014). South African higher education learning analytics pre-conference workshop. Retrieved from

http://sahela.co.za/index.php/conference-information/programme

Samzugi, A.S. \& Benhajj S. (2001). Implication of copyright protection to distance education in Tanzania: An appraisal of the Copyright and Neighbouring Rights Act, 1999.Huria, Journal of Open University of Tanzania, 3(2),99-132.

Samzugi, A.S. \& Mwinyimbegu, C.M. (2013). Accessibility of open educational resources for distance education learners: The case of the open university of Tanzania. Huria, Journal of Open University of Tanzania, 14, 76-88.

Stewart, D.W., \& Shamdasani, P.N. (1990). Focus groups: Theory and practice. Newbury Park, CA: Sage Publications.

TESSA (2012). Project briefing note. Retrieved from http://www.tessafrica.net/files/tessafrica/Briefing_note_general_June_2012.pdf

Walji, S. (2014). Researching OER in Africa and the global South. University World News, 19(335). Retrieved from http://www.universityworldnews.com/article.php?story=20140917111818454

Wright, C.R., \& Reju, S.A. (2012). Developing and deploying OER in sub-Saharan Africa: Building on the present. The International Review of Research in Open and Distance Learning, 13(2). Retrieved from http://ww.irrodl.org/index.php/irrodl/article/view/1185/2161

\section{Athabasca University}

